\title{
Fundamentos Teórico Epistemológicos de los Imaginarios Sociales
}

\author{
SOCIAL IMAGINARY THEORETICAL-EPISTEMOLOGICAL BASIS
}

Dr. José Cegarra (upelcegarra@gmail.com) Núcleo de Investigación de Estudios y Crítica Cultural de América Latina y el Caribe, Universidad Pedagógica Experimental Libertador (Táchira, Venezuela)

\begin{abstract}
This paper aims to analyze social imaginary theoretical-epistemological basis. First, it defined the term social imaginary in relation to other similar or derivative, imagination, social representation and others. They settled their differences and finally developed the ideas of the most important authors on the subject, Moscovici, Abric, Castoriadis, Durand, Carter, Baeza, Pintos. It was concluded that the social imaginary are 1) interpretations in reality, 2) socially legitimized, 3) material manifestation as speech, symbols, attitudes, affective appraisals, knowledge legitimated 4) historically developed and modified, 5) as matrices for social cohesion and identity, 6) distributed primarily through school, media and other social institutions, and 7) committed to the hegemonic groups.
\end{abstract}

Keywords: Social imaginary, social representation, interpretive schemes, symbols, matrices of meaning.

\section{Resumen}

El presente trabajo tiene como propósito fundamental analizar los fundamentos teórico-epistemológicos de los imaginarios sociales. En primer lugar, se delimitó el término imaginario social con respecto a otros similares o derivados; imaginación, representación social y otros. Se establecieron sus diferencias y finalmente, se desarrollaron las ideas de los autores más relevantes sobre el tema (Moscovici, Abric, Castoriadis, Durand, Carretero, Baeza, Pintos). Se concluyó que los imaginarios sociales constituyen 1) esquemas interpretativos de la realidad, 2) socialmente legitimados, 3) con manifestación material en tanto discursos, símbolos, actitudes, valoraciones afectivas, conocimientos legitimados, 4) históricamente elaborados y modificables, 5) como matrices para la cohesión e identidad social, 6) difundidos fundamentalmente a través de la escuela, medios de comunicación y demás instituciones sociales, y 7) comprometidos con los grupos hegemónicos.

Palabras clave: imaginarios sociales, representación social, esquemas interpretativos, símbolos, matrices de sentido.

\section{Introducción}

El presente trabajo tiene como propósito analizar los fundamentos teórico-epistemológicos de los imaginarios sociales. Esta categoría de análisis sociológico tiene ya un amplísimo desarrollo, pero aún genera debates y controversias. Por esta razón, se desea presentar este texto como una contribución para su estudio. Por supuesto, abordar el tema de los imaginarios sociales no deja de tener ciertas complicaciones. En primer lugar, por las objeciones derivadas de una larga hegemonía empírico-racionalista que negaba la 
posibilidad de implementación de métodos distintos a los naturales y que no estuviesen basados en la lógica tradicional. Indudablemente, el símbolo, la imaginación, lo imaginario, eran rechazados como fuentes de conocimiento científicamente plausible. Esta exigencia nomotética, como única forma válida y reconocida del proceder científico, se impuso durante largos años. Sin embargo, en los últimos años han sido amplias y rigurosamente elaboradas distintas discusiones teóricas que han señalado tales reduccionismos al estudiar la realidad social y la necesidad de implementar enfoques, métodos y metodologías distintas que permitan una aproximación más "pertinente" y que dé cuenta de esa complejidad. Maffesolí se refiere al punto de la siguiente manera: "urge que el discurso sobre lo social escuche con más atención al discurso de lo social, aunque la incoherencia de éste pueda molestar a las inteligencias rigurosas formadas en el racionalismo de las Luces. El rigor excesivo se aleja de lo real y la advertencia de Leibniz tiene actualidad para el sociólogo: cave a consequentiariis: cuidado con los engaños de la lógica, que ciegan ante la labilidad de las cosas, ante su avance dificultoso" (1993:52).

Para Maffesoli la realidad social es imposible de "comprender", capturar o medir en su totalidad. Es necesario aproximarse desde una "multiplicidad de intervenciones" (económicas, políticas, culturales, administrativas y cotidianas) que constituyen la mayor parte de la trama social. Así el estudioso tendrá un "mapa impresionista" que cada época y cada sociedad construyen para sí misma. Según Maffesolí esto estaría muy distante del universalismo positivista o de la generalización homogeneizante de las explicaciones inductivas; además abarcaría lo que denomina una sociología comprensiva a diferencia de la creencia en la abarcadora totalidad de la realidad. De tal forma que no existiría una única "verdad", sino distintas formas de verdad.

\section{La imaginación relegada}

Aceptada la anterior premisa epistemológica sobre la comprensión y aprehensión del mundo social desde la pluralidad metodológica y multidisciplinaria; es pertinente entonces ahora deslindar los límites teóricoepistemológicos sobre el imaginario social, así como aquellos otros conceptos cercanos o derivados: imaginación, representación colectiva, representación social, entre otros.

La imaginación como se ha sostenido anteriormente había sido reducida culturalmente a determinados campos del saber, en especial del arte y del pensamiento común. Su implementación a otros ámbitos del conocimiento cercanos al científico le era negada. En un libro titulado "Historia de la imaginación viciosa", Zolla revisa el papel de la imaginación y cómo la civilización occidental la ha tratado de regular, normar, negar e incluso minimizar como elemento fundante del conocimiento. Incluso explica que "en el uso antiguo, imaginación y sueño son con frecuencia sinónimos de opinión y de apariencia, es decir, juicio subjetivo" (Zolla 1968:49), lo cual equivalía a engaño e incluso falsa conciencia sobre las cosas. Más adelante añade: "Fueran cuales fueren los significados con que se concebía la imaginación -como una fantasía opuesta al juicio maduro, o bien como la vena fantástica de los pobres melancólicos- nunca hubo dudas acerca de su índole perniciosa y la educación procuraba desarraigarla" (Zolla 1968:50). Aún en la actualidad, la imaginación posee una valoración negativa, y sólo se le acepta como una vía para evadir la realidad por las grandes mayorías, con fantasías y ensoñaciones bajo relatos-iconos de poca significación y originalidad.

Así debe ser entendida aquella más como el fantaseo, propio de una sociedad cuyos medios de comunicación, a través de la publicidad por ejemplo, ponen en escena fetiches, objetos de consumo, construidos en mundos fantásticos y con relatos propios de la inmediatez y vacuidad de esta época. Mientras que la "imaginación buena", la que practican aquellos hombres capaces de orientar su espíritu 
creador, se asumirá también bajo los mismos patrones de consumo cultural, alejándola del poder revelador y auto reflexivo del arte, razón última que explicaría actualmente su papel como objeto de intercambio comercial y cuya fuerza autocrítica queda totalmente desvalorada. En resumen, la imaginación debe ser entendida entonces como un estado de producción y reproducción de imágenes (Ferrater Mora), sean cuales fueren éstas.

Ugas (2007:49) la define como una actividad mental que se expresa a través de imágenes, las cuales representan contenidos de conciencia. A su vez, la distingue en aquella que se rige por asociación y por reproducción. La considera una facultad básicamente individual, que participa de lo colectivo en tanto éste es fuente de las impresiones necesarias de aquella. Por su parte, Simón, a partir de los planteamientos de William James, la considera como la capacidad de "reproducir copias de los originales una vez percibidos" (2002:643) y también igualmente las clasifica en reproductiva y productiva, tal como se definía anteriormente.

En este sentido, debe establecerse una diferencia entre imaginación e imaginario. Ambos términos difieren entre sí a pesar de su proximidad etimológica. Puede resumirse que la imaginación es una capacidad individual, que parte de la realidad social para imitarla o re-crearla, y que remite al uso de imágenes como vehículos de su manifestación y está socialmente reconocida. Su primordial diferencia con el imaginario social es que éste no es una facultad humana, en tanto proceso cognitivo y emocional. El imaginario social constituye una "gramática", un esquema referencial para interpretar la realidad socialmente legitimada construido intersubjetivamente e históricamente determinado. La imaginación es representativa, el imaginario interpretativo. A fin de precisar aún más esta diferencia se asume el planteamiento de Ugas, quien señala que "la imaginación es una actividad mental que se expresa mediante imágenes en las cuales distinguimos el contenido de un acto, vale decir representar, o sea, producir contenidos de conciencia” (2007:49). Y unos líneas más adelante también plantea esa diferencia al señalar que "el imaginario es la codificación que elaborar las sociedades para nombrar una realidad; en esa medida el imaginario se constituye como elemento de cultura y matriz que ordena y expresa la memoria colectiva, mediada por valoraciones ideológicas, auto-representaciones e imágenes identitarias" (Ugas 2007:49). En otras palabras, la imaginación reproduce y recrea la realidad a partir de imágenes; mientras que el imaginario debe asumirse como una matriz de significados que orienta los sentidos asignados a determinadas nociones vitales (amor, el mal, el bien) y nociones ideológicamente compartidas (la nación, lo político, el arte, etc.) por los miembros de una sociedad. En conclusión, la diferencia fundamental entre una y otra estriba es que la imaginación es una innata facultad humana y el imaginario social, una condición o regulación externa como característica propia de la vida en sociedad.

\section{Los límites difusos: Representación e imaginario}

Las representaciones sociales han sido desarrolladas a partir de las concepciones de Moscovici. Dicho autor incluso advertía la complejidad existente para una definición precisa por poseer una "posición mixta" al ser una especie de "encrucijada" de conceptos sociológicos y psicológicos. Sin embargo, a pesar de esa complejidad, desarrolla toda una teoría desde la psicología social. Según él: "La representación social es una modalidad particular del conocimiento, cuya función es la elaboración de los comportamientos y la comunicación entre los individuos. La representación es un corpus organizado de conocimientos y una de las actividades psíquicas gracias a las cuales los hombres hacen inteligible la realidad física y social, se integran 
en un grupo o en una relación cotidiana de intercambios, liberan los poderes de su imaginación" (Moscovici 1979:17).

Moscovici considera que permiten la inteligibilidad del mundo social y físico a través de esquemas que permiten su interrelación con otros. Más adelante añade: “Las representaciones sociales son entidades casi tangibles. Circulan, se cruzan y se cristalizan sin cesar en nuestro universo cotidiano a través de una palabra, un gesto, un encuentro. La mayor parte de las relaciones sociales estrechas, de los objetos producidos o consumidos, de las comunicaciones intercambiadas están impregnadas de ellas. Sabemos que corresponden, por una parte, a la sustancia simbólica que entra en su elaboración y, por otra, a la práctica que produce dicha sustancia, así como la ciencia o los mitos corresponden a una práctica científica y mítica" (Moscovici 1979:27).

En otras palabras, estos "esquemas" permiten la inteligibilidad del mundo y la actuación sobre él. Poseen una materialidad dada a partir de los distintos discursos sociales y símbolos que circulan en la esfera social. Cada representación social se manifiesta entonces como parte del cuerpo de conocimientos sociales necesarios para interactuar e interpretarlo.

Abric define la representación social como "una visión funcional que permite al individuo o al grupo conferir sentido a sus conductas, y entender la realidad mediante su propio sistema de referencias y adaptar y definir de este modo un lugar para sí" (2001:13). Obsérvese, que al igual que Moscovici, considera que regulan tanto al individuo como al grupo y le confiere sentido a sus conductas como a la realidad misma. Otra idea importante que desarrolla Abric se refiere a las funciones que cumple: 1) funciones de saber: permiten entender y explicar la realidad, 2) funciones identitarias: definen la identidad y permiten la salvaguarda de la especificidad de los grupos, 3) funciones de orientación: conducen los comportamientos y las prácticas y 4) funciones justificadoras: permiten justificar a posteriori las posturas o comportamientos. Abric considera fundamental el papel de las funciones de las representaciones sociales para la compresión de la realidad social por poseer un carácter informativo y explicativo, derivando a su vez las prácticas sociales.

Para establecer la diferencia con el imaginario social se acudirá a dos concepciones teóricas planteadas por los autores ya mencionados. Moscovici considera que una de las principales características de las representaciones consiste en su carácter de experiencia previa, su posterior aprehensión en tanto lo designado, "en resumen, se observa que representar un objeto es al mismo tiempo conferirle la categoría de un signo, conocerlo haciéndolo significante. Lo dominamos de un modo particular y lo 'internalizamos, lo hacemos nuestro'. En verdad es un modo particular, porque llega a que toda cosa sea representación de algo" (1979:38). Por su parte Abric plantea que "es un sistema de pre-decodificación de la realidad puesto que determina un conjunto de anticipaciones y expectativas (2001:13). Puede observarse que ambos atribuyen su condición de experiencia previa, percibida y aprehendida por los individuos para después ponerla en práctica en atención a las circunstancias. En otras palabras, las representaciones sociales se forman en el individuo una vez que éste interacciona con su entorno social, lo cual le permite aprehender cognitivamente lo socialmente dado.

Mientras que para Baeza, "la teoría de los imaginarios sociales sostiene, por el contrario, que más allá de cierto plano de descripciones fundamentales, y sobre todo cuando ese algo no se da completamente en la superficie y en una apariencia concreta, la tarea que se asigna la actividad mental es la de construcción plausible -o convincente- de realidad" (2004:3). En otras palabras, las representaciones sociales son 
precodificaciones porque codifican un conjunto de anticipaciones y expectativas, es decir, el individuo debe tener una experiencia previa que le imprimirá esa representación, he allí lo subjetivo; lo colectivo será porque esa representación dependerá de la sociedad en la cual vive, pues eso mediará la forma de vivirla, actuarla y representarla. Es una dualidad subjetiva y social. Por otro lado, el imaginario social es de mayor envergadura pues es una matriz de sentido determinado que hegemónicamente se impone como lectura de la vida social. El sujeto simplemente "lo padece" por encima de sus propias experiencias vitales. Esto no quiere significar que los imaginarios sociales sean inmodificables o históricamente permanentes, por el contrario, cada época histórica a través de los grupos sociales construye o resignifica los sentidos que desea socialmente transmitir. De allí que se hable de imaginarios sociales dominantes y dominados, pero en esencia, son esquemas interpretativos para el sentido social hegemónicamente impuestos haciendo plausible la vida cotidiana.

Ahora bien el imaginario social es un término que ha tenido una historia no menos larga y actualmente mucho más compleja, tal como lo demostró Angel Carretero (2001): “En la perspectiva en la que nos movemos, interesa destacar que lo imaginario recupera una autonomía a partir de lo cual no se resigna a ser aprehendido desde ninguna actitud reduccionista, que lo convierta en la expresión de una carencia real y un sustituto irreal a dicha carencia. Desde este punto de vista, la esencia de lo imaginario adquiere un carácter propio, no se concibe como una consecuencia derivada de una causa siempre real o un antídoto quimérico de ésta, tal como es analizado en otros discursos teóricos contemporáneos, sino como un orden experiencial diferente y con una lógica propia" (2001:124).

Aunque a pesar de tal señalamiento también realiza una revisión teórica del imaginario desde los griegos, continúa con el pensamiento renacentista, el contemporáneo y el actual. En este último punto logra explicar cómo los imaginarios sociales han sido asumidos desde diversas perspectivas teóricas con Durand (cercano a la antropología), Castoriadis (al psicoanálisis), Ledrut (a la mitología), Balandier (a la sociología) y Maffesoli (a la filosofía), entre otros. Pero tal como argumenta más adelante, Carretero centra su interés en cuatro autores a pesar de las evidentes diferencias entre éstos en atención a los propósitos de su propio trabajo.

Para terminar con Carretero convendría tomar también una de las premisas que éste asume sobre los imaginarios. Considera en primer lugar que "interesa ligar, específicamente, la noción de imaginario social con los procesos de construcción social [...] analizando los efectos producidos en el terreno de la creación de realidades" (2001:251). Este punto es el que interesa, pues ayudaría a comprender cómo se configuran los imaginarios y sus implicaciones sociales, culturales, educativas o políticas, si se asumen los imaginarios como "significación" y "creación de realidades". En dicho orden de ideas, se realiza esta revisión desde la perspectiva de distintos autores, disciplinas y corrientes, mas no en atención a una posible historiografía del término.

Desde la perspectiva de la denominada antropología simbólica, Durand desarrolla y explica las bases antropológicas del imaginario. En primer lugar, Durand manifiesta que el pensamiento de la filosofía occidental $y$, en especial, la francesa, tiene como tradición la desvaloración ontológica de la imagen y psicológicamente, la imaginación por considerarla "señora del error y la falsedad". Por otra parte, critica la fallida aproximación fenomenológica, semiológica y sociológica a los imaginarios, abogando por el camino de la antropología para su verdadera comprensión. Por ello, lo considera un "trayecto antropológico, o sea, el incesante intercambio que existe en el nivel de lo imaginario entre pulsasiones subjetivas y asimiladoras y las intimaciones objetivas que emanan del medio cósmico y social” (Durand 2005:43). 
Durand emplea como método de trabajo el principio de convergencia que, a manera de resumen, puede ser entendido a través de la siguiente fórmula lógica. La convergencia es del tipo que " $A$ es a $B$ lo que $A$ ' es a B" (2005:46). Puede entenderse también de la siguiente manera: una imagen gira en torno a una "constelación de símbolos" y significaciones isomórficas entre sí. Por supuesto, la idea de imagen remite al valor arquetipal de la rememoración de un imaginario que de cuenta de la existencia humana, y estos conjuntos simbólicos expresan su sentido, significación social y antropológica. Para ello recurre al estudio de los imaginarios basado en la estructuración binaria de la representación del mundo. Aquello que Foucault llamaría identidad y otredad: día y noche, frío y caliente, y toda la gama de relaciones antagónicas pero necesariamente complementarias, pues una no puede existir sin la otra. La identidad encierra en sí misma su propia otredad. Aunque en la actualidad esta relación binaria se encuentra en entredicho, y el mismo Durand lo advierte en el prefacio a la onceava edición del texto en cuestión, pues sus propias conclusiones derivaron en una clasificación terciaria, lo cual consideraba una colisión entre ellas. Sin embargo, lo plantea como una crítica de su propio trabajo, mas no la realiza.

Durand establece entonces una clasificación de las imágenes como una arquetipología de la binariedad del mundo humano con raíces antropológicas fundamentalmente. Por ejemplo, el imaginario social viene dado en el bestiario que acompaña la cultura. Bastaría revisar en las narraciones folklóricas, mitos, leyendas populares y demás formas discursivas la vasta presencia de animales. Para el imaginario social, a los animales se les han atribuido cualidades que no le son propias. Al respecto, Durand expone lo siguiente: "Por lo demás es notable que los niños jamás hayan visto la mayoría de los animales con los que sueñan ni los modelos de imágenes con las que juegan. De igual modo, se comprueba que existe toda una mitología fabulosa de las costumbres animales que la observación directa sólo podría contradecir. Y sin embargo, para nuestra imaginación, la salamandra permanece ligada al fuego, el zorro, a la astucia, la serpiente sigue 'picando' a pesar del biólogo, el pelícano se abre el corazón, la cigarra nos enternece mientras que el gracioso ratón nos repugna. Lo cual implica hasta qué punto esta orientación teriomorfa de la imaginación forma una capa profunda, que la experiencia jamás podrá contradecir; a tal punto que el imaginario es remiso al desmentido experimental" (2005:73).

Estos símbolos teriomorfos, es decir, representaciones de propiedades humanas en lo animal, están cargados de asociaciones que revelan a la imaginación humana su propia respuesta frente a la angustia a lo desconocido, asumiendo y generando los esquemas interpretativos derivados de aquellas imágenes arquetipales que se proyectan desde el inconsciente colectivo. El imaginario funciona así como el conjunto de imágenes interrelacionadas que constituyen el pensamiento social y colectivo. En otras palabras, el imaginario da sentido a la realidad socialmente compartida pero en términos antropológicos, es decir, desde lo esencialmente humano. Por ejemplo, el bestiario que acompaña a la niñez no sólo simboliza nociones arquetipales sobre lo humano: la astucia en el zorro o la sabiduría del búho; además, consolida los sentidos de eso humano atribuidos y valorados por la cultura en la cual el infante se desarrolla. Constituye una fuente de sentidos y significados de lo que significa ser humanos.

Posteriormente, continúa desarrollando su trabajo bajo la agrupación del régimen diurno de la imagen, en el cual incluyó los símbolos teriomorfos, los símbolos nictomorfos, los símbolos catamorfos. Igualmente, añade los símbolos ascencionales, los símbolos espectaculares y los símbolos diairéticos. Como idea síntesis podría decirse que el régimen de la luz, que equivale al bien, lo bueno, triunfa en una idea de ascensión. Sobre el régimen nocturno de la imagen, de la oscuridad, equivale al descenso, al viaje que lleva al "interior", es un descenso que a veces incluso necesita de un guía, un tutor capaz de orientarnos en esa búsqueda propia de 
las más profundas revelaciones. En la literatura se observa la presencia de esta imagen arquetipal del "descenso". El viaje del héroe representa mucho más que una estructura narrativa recurrente en gran parte de la literatura occidental, además es una imagen arquetipal de la "búsqueda del héroe" como imaginario del aprendizaje espiritual del hombre, en su viaje físico o al interior de sí, todo héroe aprende algo, se le revela algo, que será fundamental para su posterior ascención. Recuérdese a Dante y su descripción del descenso al infierno o en la Biblia con la caída del hombre. En ambos ejemplos, la caída, el descenso, serán una oportunidad para la autoreflexión y la mirada interior. La cultura occidental está cargada de ese imaginario, bastaría revisar la abundante narrativa existente y comprobarlo. Este imaginario estaría en la base antropológica de la cultura y su estudio es lo que Durand desea realizar.

Los imaginarios también han sido fuente y materia de estudio del historiador de las ideas y las mentalidades. Autores como Jacques LeGoff criticaban la noción de historia asumida hasta entonces y abogaba por una historia de las representaciones. Esta a su vez la divide en distintas vertientes. De interés particular debe comentarse con LeGoff la historia de "las producciones del espíritu vinculadas no con el texto, las palabras, el gesto, sino con la imagen o la historia de lo imaginario, que permite tratar el documento literario y el artístico como documentos históricos a título pleno, con la condición de respetar su especificidad" (1995:13).

Incluso añade que toda historia eficaz debe reconocer lo simbólico en todas las realidades históricas y confrontar las representaciones con la realidad que representan. Como ejemplo, podría sugerirse que gran parte del conocimiento que se posee sobre la cultura griega, por ejemplo, de sus prácticas sociales se le debe al texto de la llíada de Homero. El texto literario junto a otros documentos y monumentos, métodos y fuentes, contribuyen a una comprensión más amplia de la cultura griega en su cotidianidad, sus creencias, costumbres; que abordarla desde métodos histórico tradicionales. Por supuesto, LeGoff establece sus premisas desde posturas epistemológicas distintas que define su objeto y sus métodos. Este enfoque demuestra que 1) los imaginarios sociales tienen una materialidad tangible en los documentos y monumentos erigidos por las sociedades. Por tanto, pueden ser objeto de análisis como evidencia empírica. 2) Los imaginarios sociales son históricamente reconocibles y constituyen fuente para la comprensión de los "esquemas interpretativos" de los grupos sociales. 3) El historiador recurre a distintas fuentes como el mito, lo literario, la escultura, arquitectura y otras tantas prácticas sociales humanas que revelan un simbolismo y un sentido que puede ser "descifrado" históricamente, dando claves sobre distintos aspectos de la vida cotidiana que bajo otros métodos sería imposible captar.

Otro autor inscrito en esta concepción de la historia y que también aborda su estudio desde los imaginarios sociales es Bronislaw Baczko. Inicia sus planteamientos recordando que esta valoración de los imaginarios pone en duda la tradición intelectual del "cientificismo realista" y "desmitificador". Según este historiador existe una visión que aún considera los imaginarios sociales como una especie de adorno de las relaciones económicas, sociales, políticas, etc; pero las ciencias humanas no lo asumen precisamente como "irreal", al menos entre comillas. Coloca como ejemplo todos los significados que poseen las representaciones del poder en los emblemas de los partidos políticos, movimientos sociales, entre otros. Estos objetos se encuentran cargados de significaciones, se constituyen en símbolos del poder y quien los usa se enviste de éste. Existe pues un imaginario asociado a símbolos específicos y legitimados socialmente. Bastaría recordar los tronos, cetros, capas, unciones y demás símbolos que los reyes empleaban, lo cual evoca a ese imaginario de poder y por tanto los otros, en este caso los súbditos, a su vez asumían determinado comportamiento, actitud, mediando sus relaciones sociales en atención a ese imaginario. 
Baczko señala puntualmente que una sociedad sólo podría existir y mantenerse, asegurando un mínimo de cohesión y consenso, en la medida que los individuos preponderan el carácter colectivo sobre el individual: "un sistema de creencias y prácticas que unen en una misma comunidad, instancia moral suprema, a todos los que se adhieren a ella" (1991:21). Por supuesto, esto únicamente se lograría a través de símbolos, exteriores a los actos de conciencia del individuo, pero asumidos como realidades. El hecho social es fundamentalmente simbólico. Este imaginario elegido más o menos arbitrario puede significar unas cosas e impulsar otras prácticas sociales. Aquí reposa el carácter del imaginario como "esquema interpretativo" que hace plausible la realidad social. Añade: "La vida social, de este modo, es productora de valores y de normas y, por consiguiente, de sistemas de representación que los fijan y los traducen" (1991:22). Baczko además expone que con los imaginarios la colectividad define su identidad construyendo su propio sistema de referencias. Así el imaginario regula la acción social. Designar esa "identidad colectiva" implica consiguientemente "marcar su territorio, y las fronteras de éste, definir sus relaciones con los otros, formar imágenes de amigos y enemigos, de rivales y aliados; del mismo modo, significa conservar y modelar los recuerdos pasados" (1991:28). Así la idea de nación debe su origen o efectividad, al menos simbólicamente, al imaginario que se constituye sobre ella. En efecto, el imaginario de nación se apoya en esa idea de la identidad colectiva, histórica y socialmente construida desde los símbolos hasta las creencias, mitos fundacionales y otros discursos constitutivos de lo nacional. Al considerarse un "esquema de interpretaciones [y de] valoración, el dispositivo imaginario provoca la adhesión a un sistema de valores e interviene eficazmente en el proceso de su interiorización por los individuos, moldea las conductas, cautiva las energías, y llegado el caso conduce a los individuos a una acción común" (1991:30). Baczko le asigna un papel de socialización tal como Berger y Luckmann lo caracterizaban. El imaginario interviene en distintos niveles de la formación y construcción permanente de la compleja trama social.

Por otra parte, Baczko también problematiza el papel de la alfabetización y los medios de comunicación en la difusión de los imaginarios sociales. Considera que el impacto de aquellos sobre las mentalidades depende fundamentalmente del control que se posea de esos circuitos. El dominio simbólico será posible sólo si se controlan esos medios que constituyen otros tantos "instrumentos de persuasión, de presión, de inculcación de valores y de creencias" (1991:31). Por tanto, la escuela, los medios de comunicación de masas y otros aparatos difunden los imaginarios dominantes a fin de controlar la circulación de determinados símbolos, esquemas interpretativos y discursos legitimadores. Esta es otra característica que coincide con los argumentos sociológicos de Berger y Luckmann sobre la socialización secundaria dada en la escuela fundamentalmente. Así que podría asumirse que el imaginario de nación, indudablemente, posee una pulsión intersubjetiva, en un contexto histórico y cultural, que se difunde a partir de los discursos, símbolos y prácticas sociales desde la escuela y los medios de comunicación -puntos a desarrollar ampliamente más adelante- como esquema interpretativo de cohesión social y base del comportamiento socialmente aceptado. Finalmente, sin pretender haber reseñado totalmente las ideas de Baczko, se revisaron y asumen las conceptualizaciones más pertinentes para esa investigación con lo cual se evidencia, al menos conceptualmente, las coincidencias teóricas en torno a la categoría imaginario social.

A este punto, debe reseñarse a un teórico del imaginario social que ha servido de base para casi todos los estudios que se han desarrollado con esta categoría: Cornelius Castoriadis. Para Castoriadis el psicoanálisis, la filosofía y la reflexión sobre el lenguaje marcan el recorrido de lo que llama su "elucidación", pues cualquier pretensión de teoría pura, sería ficción. De igual forma advierte que lo que algunos llaman "imaginario" como "imagen de" no se corresponde con su concepción de imaginario: "Lo imaginario del que hablo no es imagen de. Es creación incesante y especialmente indeterminada (histórico-social y psíquica) de 
figuras / formas / imágenes, a partir de las cuales solamente puede tratarse de 'alguna cosa'. Lo que llamamos 'realidad' y 'racionalidad' son obras de ello" (Castoriadis 2007:12).

Castoriadis cuestiona esa idea de "imagen de" pues convierte a la teoría en una "mirada" sobre lo que es. Así evita denominar teoría a su trabajo y prefiere denominarlo "elucidación" entendida como "el trabajo por el cual los hombres intentan pensar lo que hacen y saber lo que piensan" (2007:12). Esa es una de sus primeras consideraciones, pues Castoriadis plantea que toda "elucidación" es histórico-social, y no puede aspirar ser abarcadora tal como la teoría tradicionalmente se justificaba. Por tanto, todo conocimiento es un proyecto histórico y político.

Su texto La institución imaginaria de la sociedad lo asume como "heterogéneo", pues aborda distintos temas, aunque interrelacionados entre sí. Sin embargo, es de particular interés revisar sólo lo referido al imaginario social. Castoriadis plantea que todo lo dado en lo histórico-social está indefectiblemente ligado a lo simbólico. Por supuesto, los actos reales, individuales y colectivos, entendidos como el consumo, el amor, la guerra, no son directamente símbolos; pero tampoco pueden tener su existencia fuera de una red simbólica. Cada objeto y cada acto existe per se de la percepción que se tiene de éste, aunque su existencia depende básicamente del tejido simbólico en el cual se inserta. Una silla es una silla, indudablemente, pero puede simbolizar el poder si responde a un trono de un rey. Posee esa significación incluso sin que el rey esté sentado sobre ella, la use siempre o no: los atributos simbólicos son elaborados en lo histórico-social del imaginario.

Con respecto a las instituciones, plantea que tampoco se reducen a lo simbólico, pero tampoco podrían existir sin ello. Incluso añade que representan una suerte de símbolo en segundo grado y cada una posee su propio sistema simbólico: "Una organización dada de la economía, un sistema de derecho, un poder instituido, una religión, existen socialmente como sistemas socialmente sancionados. Consiste en ligar a símbolos (a significantes) unos significados (representaciones, órdenes, conminaciones o incitaciones a hacer o a no hacer, unas consecuencias, unas significaciones, en el sentido lato del término) y en hacerlos valer como tales, es decir, hacer este vehículo más o menos forzado para la sociedad o grupo considerado" (2007:187).

El dinero sería un ejemplo de tal sistema simbólico. Con ese objeto físico y simbólico se pueden realizar otros actos igualmente simbólicos como comprar otros objetos, pagar por un servicio, o incluso se derivan otros actos alrededor suyo pues depende del valor sancionado del objeto o servicio la cantidad misma de dicho dinero, que podría variar también a su vez por el tipo de relación social entre los individuos pertenecientes al mismo estrato socioeconómico o no, convirtiéndose en un entramado de relaciones simbólicas todas pertenecientes a un sistema simbólico dado. De esta forma, la sociedad constituye su simbolismo pero nunca en total libertad, pues "se agarra de lo natural, y se agarra de lo histórico (a lo que ya está ahí); participa finalmente en lo racional. Todo esto hace que emerjan unos encadenamientos de significantes, unas relaciones entre significantes y significados, unas conexiones y unas consecuencias a los que no se apuntaba, ni estaban previstos. Ni libremente elegido, ni impuesto a la sociedad considerada [...] el simbolismo a la vez determina unos aspectos de la vida y de la sociedad (y no solamente aquéllos que se suponía que determinaba) y está lleno de intersticios y grados de libertad" (2007:201).

Así que la sociedad vive una pulsión entre el simbolismo institucional y lo históricamente dado. No podría imaginarse a ninguna sociedad atrapada por el simbolismo de sus instituciones, por el contrario, la cultura occidental ha tratado de dominar el simbolismo tanto del lenguaje como el de sus instituciones. 
Era necesario precisar estas ideas, pues para Castoriadis el imaginario emplea lo simbólico para expresarse e incluso para "existir". De allí que argumente que en la medida que la capacidad de "hacer surgir" una imagen de algo que no es, ni fue, se estará en presencia de un imaginario radical o imaginario efectivo. Existe una influencia definitiva del imaginario sobre lo simbólico y que éste presupone a aquel. El imaginario radical surge de lo natural, no está predeterminado por causa alguna, surge permitiendo pensar en lo no imaginado, en la posibilidad de otro "imaginado". Los individuos del imaginario radical disponen de significantes socialmente dispuestos, que le permiten transformar las imágenes en símbolos.

En resumen, para Castoriadis el imaginario social, o lo social instituyente, es creación de "significaciones imaginarias sociales y de la institución", pues como institución es "presentificación" de significaciones tal como están instituidas. Por su parte, el imaginario radical es creación como presentificación de sentido siempre figurado-representado. El imaginario radical es entonces un fenómeno individual antes que social, que se presenta relativamente libre e irreductible a cualquier tipo de racionalidad. Luego este imaginario individual pasa a ser social por la necesidad humana de establecer relaciones sociales en su existir y se colectiviza no como una suma de imaginarios individuales, sino gracias a condiciones históricas dadas y sociales favorables para lograr ser instituidos.

Por su parte, José Luis Pintos, otro reconocido estudioso del imaginario social, plantea una definición igualmente próxima a las anteriormente citadas. Define los imaginarios sociales como "aquellas representaciones colectivas que rigen los sistemas de identificación y de integración social y que hacen visible la invisibilidad social" (1995:8). Lo imaginarios "hacen visible lo invisible", es decir, las regulaciones sociales adquieren "materialidad" sólo cuando son puestas en escenas a través de las actuaciones debidamente sancionadas y reguladas de los comportamientos individuales. Cada acto individual de lo cotidiano o del mundo de la vida da cuenta de los imaginarios como esquemas de esa integración social, a su vez permite el reconocimiento de los otros y de sí mismo como sistema de identificación.

Según otra definición de Pintos los imaginarios sociales serían "aquellos esquemas, construidos socialmente, que nos permiten percibir algo como real, explicarlo e intervenir operativamente en lo que en cada sistema social se considere como realidad" (1999:5). En otras palabras, deben ser asumidos como toda aquella mediación entre lo que se asume como realidad y lo que se percibe, acepta, reconoce o legitima de esa relación. Pintos establece una excelente metáfora: los imaginarios son como lentes o anteojos que se tienen, pero sin sentirlos como tales, pues sólo así permiten "ver" mejor el mundo. También expresa de manera explícita sus diferencias con aproximaciones psicoanalíticas o de naturaleza similar para comprender los imaginarios, pues considera que éstos son producidos por la interacción de las instituciones socialmente reconocidas, además de la condición de crisis de sentido de estos tiempos. La siguiente cita aunque extensa expresa puntualmente dicha concepción: "Las evidencias básicas, de las que vivimos y en las que creemos o estamos (como afirma Ortega), no se generan mediante 'representaciones' colectivas que los individuos copiamos en nuestro comportamiento cotidiano, ni tampoco mediante 'conciencias colectivas' o 'arquetipos' procedentes de estadios anteriores de la humanidad. Nuestras evidencias provienen de las plurales referencias emitidas recursivamente por las instituciones que pugnan entre sí por definir realidades creíbles. No es cierto que nos hayamos quedado sin referencias, sin valores, sin ideales. Lo que sucede es que han desaparecido los absolutos que les daban a unas u otros la categoría de únicos. Vivimos en unas sociedades en las que las formas de entrelazarse las experiencias y las ideas, los tiempos y los espacios, las historias y los proyectos no sólo presentan diferentes tramas y figuras, sino que el primer derecho que reclama el individuo es el derecho a la diferencia. No porque ya se haya conseguido la igualdad (y la libertad, 
y la fraternidad), sino porque no nos sirven los caminos o modelos que construyeron las anteriores generaciones sobre la exclusión de la mayoría de los tipos de racionalidad que constituyen nuestra vida. Estas sociedades en las que vivimos son por ello policontexturales" (1999:9).

Obsérvese entonces que las instituciones -entiéndase escuela, medios de comunicación, industrias culturales- emiten recursivamente referencias de sentido, a través de los imaginarios, haciendo plausible la realidad socialmente dada. $Y$ aunque ahora se percibe una ausencia o crisis de sentido, lo que realmente ocurre es que en la actualidad aquellos tiempos de certezas, de relaciones unívocas entre cosas y palabras, de la identidad (mismidad) como principio ordenador del mundo (Foucault), simplemente se deslegitimaron o al menos ya no son reconocidas: perdieron su carga afectiva y simbólica. Ahora el reclamo es por la diferencia, lo cual explicaría las exigencias más frecuentes de minorías étnicas o de grupos sociales (campesinos, mujeres, negros, homosexuales, etc.); también de cambios en las sensibilidades y capacidades perceptivas frente a ese mundo hiperinformado bajo permanentes confrontaciones discursivas, políticas y culturales.

En otro texto plantea que Ledrut define a los imaginarios sociales como "esquemas de representación. Estructuran en cada instante la experiencia social y engendran tanto comportamientos como imágenes reales" (Ledrut citado por Pintos 1995:20). Así, los imaginarios "contienen la realidad" y regulan a su vez los comportamientos sociales. Pinto redefine nuevamente los imaginarios: "1. Esquemas socialmente construidos, 2. Que nos permiten percibir, explicar e intervenir, 3. En lo que en cada sistema social diferenciado, se tenga por realidad" (Pintos 2005:42). Podría asumirse que las definiciones de Pintos siempre han girado en torno a la idea del imaginario como esquema de interpretación construido y legitimado socialmente que coadyuvan al comportamiento social. Finalmente, es importante señalar que aunque Pintos es fundamentalmente constructivista, conserva una proximidad teórica, al menos en lo que se refiere a los imaginarios, con los autores reseñados anteriormente.

Otro autor que coincide con estos planteamientos de Pintos es Manuel Antonio Baeza, quien se refiere a los imaginarios sociales como "múltiples y variadas construcciones mentales (ideaciones) socialmente compartidas de significancia práctica del mundo, en sentido amplio, destinadas al otorgamiento de sentido existencial" (2004:2). Es decir, constituyen un "mecanismo" de mediación entre la realidad y "nuestra" percepción de ella. Según este autor la relación con el mundo no es puro trabajo de la percepción o simple producción interna, es mentalmente mediada, pero en una permanente interacción social. De allí que Baeza incluso afirme: "Digo entonces, con propiedad, que esas construcciones imaginarias son socialmente compartidas, o sea que se reconocen estas figuras construidas de la realidad como parte de la experiencia social, la cual se comparte gracias a la comunicación, o si se quiere, gracias a la circulación siempre presente de buena parte de la experiencia llevada a cabo en común" (2004:4).

De esta manera, no se pretende señalar una especie de homologación de las experiencias sociales, por el contrario, existen contradicciones u oposiciones entre la heterogénea experiencia socialmente compartida. Sin embargo, lo cual no sería tan evidente, es entender que sí existe una hegemonía de unos imaginarios sobre otros, producto de la legitimación que éstos adquirieren en el marco de su propia difusión, circulación y aceptación social. De allí que Baeza (2000) hable de imaginarios dominantes e imaginarios dominados, lo que representa esa "lucha" constante tratando de imponerse esa "visión del mundo" para "hacerla parecer natural". Todo el cuerpo social asumiría la que hegemónicamente se haya impuesto, aunque eso no dirima 
la confrontación, sino que minimiza el conflicto hasta tanto no aparezcan nuevas oposiciones tratando de, a través de otros imaginarios, imponerse.

Bastaría colocar como un ejemplo el caso del imaginario de nación. Podría interrogarse ¿qué símbolos configuran un imaginario de nación?, ¿cuál visión de país, patria o pueblo se impuso?, ¿cuáles tradiciones, prácticas, emblemas, músicas, valores y creencias, en fin símbolos culturales se privilegiaron por encima de otros de igual valía? He allí esa tensión, pero que final y hegemónicamente termina por un tiempo, imponiéndose uno solo, hasta una nueva crisis de sentido social que exija repensarse. Podría afirmarse que gracias a esa condición se ha mantenido la permanencia y cohesión social, pues va "actualizándose" en el devenir temporal, en los cambios sociales y culturales propios de cada nación. Baeza puntualiza también una idea que resulta esencial sobre el imaginario de nación. Según él los imaginarios sociales "matizan respuestas a enigmas de la vida social con afirmaciones fuertes, tales como 'la presencia de Dios' (en un imaginario religioso), 'el carácter sagrado de la Patria' (en un imaginario nacional), 'la objetividad indesmentible de la ciencia' (en un determinado imaginario científico), etc. Estamos en presencia entonces de eufemismos sui generis que añaden un cierto grado de seguridad y de alivio a una determinada construcción de realidad plausible" (2004:5).

Tratando de interpretar esta idea podría entenderse a través del siguiente ejemplo. La sociedad, o para ser más específicos, los grupos humanos, se desarrollan sobre un territorio, pero éste per se no instituye la carga afectiva y cultural o cualquier asociación simbólica. Será a través de los diversos imaginarios sociales que circulen en ese grupo social que la idea de nación se configure, cargada de emblemas, narrativas y mitologías fundacionales; en fin, una construcción de un "pasado (historia), presente (acción) y futuro (utopía)". Para culminar con Baeza este afirma que los imaginarios actúan como "singulares matrices de sentido o, al menos, como elementos coadyuvantes en al elaboración de sentidos subjetivos atribuidos al discurso, al pensamiento, y muy importante, a la acción social" (2000:14). En otras palabras, por un lado acompañan a la razón "modificándola creativamente" pero por otro, se oponen también a la racionalidad, complejizando la conciencia entre la realidad y la fantasía.

\section{Conclusión}

Así pues es necesario señalar que los imaginarios sociales cuentan con una extensa cantidad de publicaciones y que sin duda podrían exponerse muchos otros autores que analizan sus fundamentos teóricos y epistemológicos, tales como Deibar Hurtado, Oscar Basulto, Lucio Cerdá, Josetxo Beriain, entre otros; además del sin fin de trabajos que desde los imaginarios estudian las tecnologías, culturas juveniles, género, religión o la gran cantidad de artículos que pudieran revisarse en bases de datos como Redalyc, Dialnet, Scielo, etc., pero debe entenderse que la pretensión no fue dar cuenta de todo el amplio y profuso discurrir filosófico y científico sobre el tema. Se asumió que la mayoría de estos últimos autores mencionados, en esa especie de lista, se refieren y se apoyan en las fuentes primarias ya reseñadas detenidamente en este trabajo.

Como conclusión y en atención a los planteamientos desarrollados pudiera afirmarse que los imaginarios no pueden ser definidos en términos de un concepto preciso y unívoco tal como la ciencia social empíricaanalítica pretende. Es necesario asumir una postura epistemológica que valore otros sistemas de razonamiento científico que dé cuenta de la complejidad de los fenómenos sociales y como tal los estudie. Al respecto, todos y cada uno de los autores precisaron que más que significados, los imaginarios remiten a sentidos. Es decir, a múltiples significaciones que en conjunto conforman un marco de referencia o campo 
semántico que sirve de esquema de interpretación para comprender y aprehender la realidad socialmente dada. A modo de ejemplo podría pensarse en la palabra "amor". Difícil de delimitar en términos de una definición operacional (observable y denotativa) pero las personas "comprenden" los sentidos asociados a tal término: afecto, caricias, sentimiento, etc. y así lo asumen al ver determinadas imágenes, oír expresiones u observar comportamientos en correspondencia. Los imaginarios constituyen un repertorio de sentidos que se han legitimado en un marco social y cultural para interpretar comportamientos sociales y legitimar determinadas valoraciones ideológicas y culturales. En suma, serían un repositorio de sentidos plausibles a los cuales recurren los individuos en determinadas situaciones sociales.

\section{Bibliografía}

Abric, J. 2001. Prácticas sociales y representaciones. México: Coyoacán.

Baczko, B. 1991. Los imaginarios sociales. Memorias y esperanzas colectivas. Buenos Aires: Nueva Visión.

Baeza, M. 2000. Los caminos invisibles de la realidad social. Ensayo de sociología profunda sobre los imaginarios sociales. Concepción: Red Internacional del Libro.

Baeza, M. 2004. Ocho argumentos básicos para la construcción de una teoría fenomenológica de los imaginarios sociales. [Documento en línea]. Disponible: http://www.gceis.cl/.

Carretero, A. 2001. Imaginarios sociales y crítica ideológica. Una perspectiva para la comprensión de la legitimación del orden social. [Documento en línea]. Disponible: http://cervantesvirtual.com/.

Castoriadis, C. 2007. La institución imaginaria de la sociedad. Buenos Aires: Tusquest.

Durand, G. 2005. Las estructuras antropológicas del imaginario. México: Fondo de Cultura Económica.

LeGoff, J. 1995. Pensar la historia. Barcelona: Altaya.

Maffesolí, M. 1993. El conocimiento ordinario. Compendio de sociología. México: Fondo de Cultura Económica.

Moscovici, S. 1979. El psicoanálisis, su imagen y su público. Buenos Aires: Huemul.

Pintos, J. 1995. Los imaginarios sociales. La nueva construcción de la realidad social. Salamanca: Fe y Secularidad.

Pintos, J. 1999. Los imaginarios sociales del delito: La construcción social del delito a través de las películas (1930-1999) [Documento en línea]. Disponible: http://web.usc.es/ jlpintos/articulos/delitocine.htm..

Pintos, J. 2005. Comunicación, construcción de la realidad e imaginarios sociales. Utopía y Praxis Latinoamericana 10(29): 37-65.

Simón, V. 2002. Las trampas de la imaginación. Psicothema 14(3): 643-650.

Ugas, G. 2007. La educada ignorancia: Un modo de ser del pensamiento. Caracas: TAPECS.

Zolla, E. 1968. Historia de la imaginación viciosa. Caracas: Monte Avila.

Recibido el 9 de octubre de 2011

Aceptado el 5 de enero de 2012 